\title{
Comunicação
}

[Communication]

\section{Primeiro relato de Muscidifurax raptorellus Kogan \& Legner, 1970 (Hymenoptera: Pteromalidae) no Brasil}

[First report of Muscidifurax raptorellus Kogan \& Legner, 1970) (Hymenoptera: Pteromalidae) in Brazil]

\author{
C.H. Marchiori ${ }^{1}$, J.M. Miranda ${ }^{1}$, V.A. Costa $^{2}$ \\ ${ }^{1}$ Instituto Federal de Educação, Ciências e Tecnologia Goiano \\ $\mathrm{Br} 153-\mathrm{Km} 633$ \\ 75650-000 - Morrinhos, GO \\ ${ }^{2}$ Instituto Biológico - APTA - Campinas, SP
}

Galinhas poedeiras em granjas provocam um grande acúmulo de esterco, o qual é um excelente substrato para a proliferação de moscas. Para controle desses insetos, um programa de manejo deve integrar métodos culturais, químicos e biológicos. Os agentes de controle biológico terão maior chance de serem bem-sucedidos se forem mais adaptados à região, à época do ano e ao tipo de esterco do local (Costa et al., 2004).

Os dípteros são de grande interesse médicosanitário, e sua ocorrência, distribuição e predominância nas áreas metropolitanas são fatores de grande importância em saúde pública (Marchiori e Silva, 2001). Os adultos de Fannia pusio Wiedemann, 1830 (Diptera: Fanniidae) são frequentemente encontrados associados em ambientes modificados pelo homem, e suas larvas são criadas em matéria orgânica em decomposição (Pont, 1977).

Os parasitoides são agentes responsáveis pela redução da população de moscas que proliferam em esterco (Marchiori e Silva, 2001), cadáveres e carcaças de animais. Além disso, sendo inimigos naturais de pragas agrícolas, podem ser usados em programas de controle biológico (Scatolini e Dias, 1997).

Muscidifurax raptorellus Kogan \& Legner, 1970 (Hymenotera: Pteromalidae), oriundo da América do Sul, ocorre sob duas formas: uma gregária, no Chile e EUA, e outra solitária, no
Peru. A população gregária de $M$. raptorellus tem sido, desde então, utilizada no controle biológico nas granjas em Nebraska, Geórgia e Flórida (Kogan e Legner, 1970; Petersen e Currey, 1996a, b; Geden et al., 1998). O objetivo deste trabalho foi relatar a ocorrência de $M$. raptorellus no Brasil.

O experimento foi realizado na granja do CEFET-UNED, Morrinhos, em Goiás. As fezes coletadas originaram-se de 80 aves da linhagem Hyline. A granja é composta por dois galpões de $15 \mathrm{~m}$ de comprimento por $5 \mathrm{~m}$ de largura e $5 \mathrm{~m}$ de altura. O galpão é formado por duas fileiras de gaiolas construídas de armação de metal contendo duas aves por gaiola. As fileiras com as gaiolas ficam separadas por um corredor de cimento de $2 \mathrm{~m}$ de largura, e as gaiolas ficam suspensas do chão a $50 \mathrm{~cm}$ de altura. O piso abaixo das gaiolas e ao redor é constituído por terra. As fezes acumuladas sob as gaiolas apresentavam teor variável de umidade e sua consistência variava de pastosa a firme. Em um galpão, as fezes frescas foram coletadas imediatamente após a emissão e colocadas em quatro bacias de $30 \mathrm{~cm}$ de diâmetro por $12 \mathrm{~cm}$ de altura, as quais foram deixadas no próprio ambiente, em local seco.

As fezes permaneceram no galpão por 15 dias. Posteriormente, as bacias foram retiradas e levadas para o laboratório para a extração das pupas pelo método da flutuação. As pupas foram retiradas com o auxílio de uma peneira, contadas

Recebido em 22 de agosto de 2008

Aceito em 19 de janeiro de 2009

E-mail: chmarchiori@yahoo.com.br 
e individualizadas em cápsulas de gelatina (número 00) até a emergência dos dípteros e/ou dos seus parasitoides. Os parasitoides e os dípteros emergidos foram identificados com auxílio de um microscópio estereoscópio e, posteriormente, conservados em álcool 70\%. A porcentagem de parasitismo foi calculada dividindo o número de pupas parasitadas pelo número total de pupas coletadas, multiplicando o resultado por cem. Os exemplares de $M$. raptorellus foram identificados e depositados na Coleção de Insetos Entomófagos Oscar Monte (IB-CBE), do Instituto Biológico, em Campinas, SP.

Em outubro de 2007, foram coletadas 10 pupas de F. pusio Wiedemann, 1830, das quais emergiram dois exemplares de $M$. raptorellus, representando 5\% de parasitismo. Muscidifurax Girault \& Sanders é um gênero com apenas cinco espécies (Kogan e Legner, 1970), das quais apenas $M$. raptorellus não foi encontrada no país. Muscidifurax raptor Girault \& Sanders foi relatada por Neves e Faria (1988), Geden et al. (1998), Marchiori et al. (2000) e Marchiori e Silva (2001). M. raptoroides Kogan \& Legner foi registrada por De Santis e De Sureda (1988), M. zaraptor Kogan \& Legner foi coletada por Marchiori et al. (2000), enquanto a espécie telítoca M. uniraptor Kogan \& Legner foi observada por Berti Filho et al. (1989).

No Brasil, F. pusio foi encontrada parasitada pelos seguintes parasitoides: Eurytoma (Hymenoptera: Euritomydae), Pachycrepoideus vindemmiae (Rondani) (Hymenoptera Pteromalidae), Paraganaspis egeria Díaz, Gallardo \& Walsh (Hymenoptera: Figitidae), Spalangia drosophilae Ashmead (Hymenoptera: Pteromalidae) e Spalangia nigra Latrielle (Marchiori et al., 2005). Este trabalho relata a primeira ocorrência de $M$. raptorellus no Brasil.

Palavras-chave: Insecta, Diptera, primeira ocorrência, inimigo natural, controle biológico

\begin{abstract}
This study reports the first occurrence of Muscidifurax raptorellus (Hymenoptera: Pteromalidae) in Brazil. Chicken manure samples, collected at two-week interval, were taken to the laboratory and the pupae were extracted by the method of flotation. Each pupa was placed in capsules of colorless gelatin until the emergence of dipterous or their parasitoids. In the study, ten pupae of Fannia pusio (Wiedemann, 1830) (Diptera: Fanniidae) were obtained, two of which yielded the parasitoid M. raptorellus. The percentage of parasitism was $5.0 \%$.
\end{abstract}

Keywords: Insecta, Diptera, first occurrence, natural enemy, biocontrol

\section{REFERÊNCIAS BIBLIOGRÁFICAS}

BERTI FILHO, E.; COSTA, V.A.; AAGESEN, T.L. Occurrence of natural enemies of Musca domestica L. (Diptera: Muscidae) in poultry areas of Bastos, State of São Paulo, Brazil. Rev. Agric., v.64, p.98, 1989.

COSTA, V.A.; BERTI FILHO, E.; SILVEIRA NETO, S. Parasitoides (Hymenoptera: Chalcidoidea) de moscas sinantrópicas (Diptera: Muscidae) em aviários de Echaporã, SP. Arq. Inst. Biol. São Paulo, v.71, p.203-209, 2004.

DE SANTIS, L.; DE SUREDA, A.E.G. Himenopteros calcidoideos parasitoides de Musca domestica em América del Sur (Insecta). An. Acad. Nac. Cienc. Buenos Aires, v.21, p.5-9, 1988.
GEDEN, C.J.; BERNIER, U.R.; CARLSON, D.A. et al. Identification of Muscidifurax spp., parasitoids of muscoid flies, by composition patterns of cuticular hydrocarbons. Biol. Control, v.12, p.200-207, 1998.

KOGAN, M.; LEGNER, E.F. A biosystematic revision of the genus Muscidifurax (Hym., Pteromalidae) with descriptions of four new species. Can. Entomol., v.102, p.1268-1290, 1970.

MARCHIORI, C.H.; CASTRO, M.E.V.; PAIVA, T.C.G. et al. Dípteros muscoides de importância médica e veterinária e seus parasitoides em Goiás. Arq. Bras. Med. Vet. Zootec., v.52, p.350-353, 2000. 
MARCHIORI, C.H.; SILVA, C.G. Dípteros sinantrópicos associados a restos alimentares e seus parasitoides. Neotrop. Entomol., v.30, p.187-189, 2001.

MARCHIORI, C.H.; SILVA FILHO, O.M.; FORTES, F.C.A. et al. Parasitoides de Fannia pusio (Wiedemann, 1830) (Diptera: Fanniidae) coletados em Caldas Novas, Goiás, Brasil. Biotemas, v.29, p.1288-1291, 2005.

NEVES, D.P.; FARIA, A.C. Profundidade de empupação de Stomoxys calcitrans (Diptera, Muscidae) e presença de microhimenópteros parasitoides nas pupas. Rev. Bras. Biol., v.48, p.911-913, 1988 .

PETERSEN, J.J.; CURREY, D.M. Reproduction and development of Muscidifurax raptorellus
(Hymenoptera: Pteromalidae), a parasite of filth flies. J. Agric. Entomol., v.13, p.99-107, 1996a.

PETERSEN, J.J.; CURREY, D.M. Timing of release of gregarious Muscidifurax raptorellus (Hymenoptera: Pteromalidae) to control flies associated with confined beef cattle. J. Agric. Entomol., v.13, p.55-63, 1996b.

PONT, A.C. A revision of Australian Fanniidae (Diptera: Calyptrate). Aust. J. Zool., v.1, p.1-60, 1977.

SCATOLINI, D.; DIAS, A.M.P. A fauna de Braconidae (Hymenoptera) como bioindicadora do grau de preservação de duas localidades do Estado do Paraná. Rev. Bras. Ecol., v.1, p.84-87, 1997. 